\title{
Are Bioceramics the Dernier Cri in the Management of Stage 4 Developed Root? A Finite Element Analysis
}

\author{
Sonali Sharma ${ }^{1}$, Sanjay M Londhe ${ }^{2}$, Mithra N Hegde ${ }^{3}$, Vandana Sadananda ${ }^{4}$
}

\begin{abstract}
Aim: To compare the stress distribution of four modalities of reinforcing the radicular space of a pulpless central incisor exhibiting stage 4 root development.

Materials and methods: The model of a pulpless immature central incisor with a stage 4 of root development supporting periodontium was generated based on the properties. The longitudinal growth of the root was completed. Four such models were developed. Then, the radicular space was rehabilitated as follows: Model 1: Ceramicrete; Model 2: Biomimetic Mineralization; Model 3: Biodentine; Model 4: Bioaggregate. They were subjected to three different loading conditions. One was to mimic the mastication by applying a load of $70 \mathrm{~N}$ applied at $45^{\circ}$ angle. Second loading condition was a vertical load of $100 \mathrm{~N}$ to mimic bruxism. The third loading condition was to mirror the impact of a frontal trauma. A load of $100 \mathrm{~N}$ was applied labially.

Results: It was observed that during mastication, Model 2 has exhibited the lowest concentration of von Mises stresses, followed by Model 3 and then Model 4 followed by Model 1; this could be because the modulus of elasticity of Model 2 is comparable to that of Dentin. During bruxism and horizontal impact, the maximal stress concentration was found in Model 4, Model 3, Model 2, followed by Model 1.

Conclusion: The closer the elasticity of modulus of the primary endodontic replacement monoblock was to that of dentin, the lower were the stresses generated. However, as the increase in stress values was minimal between groups, these obturating materials can be viable reinforcement materials for the rehabilitation of cases of stage 4 developing root. Biomimetic mineralization strategies can be a viable treatment option for managing cases of the open apex.

Clinical relevance: Biomimetic mineralization strategies and bioceramics can be used for obturation of root canals with open apex, instead of utilizing these bioceramics as apical plugs.

Keywords: Bioaggregate, Biodentine, Biomimetic mineralization, Ceramicrete, Finite element analysis, Stage 4 root development, von Mises stresses.

The Journal of Contemporary Dental Practice (2020): 10.5005/jp-journals-10024-2916
\end{abstract}

\section{INTRODUCTION}

The success of root canal treatment is dependent on threedimensional cleaning and shaping, thorough disinfection, and three-dimensional obturation root canaliculi system. Proverbially, the material which is used to obturate the prepared root canal is a trans-isomer of isoprene, known as gutta-percha. The disadvantage of obturating the canals with gutta-percha is leakage, lack of adhesion to dentin, shrinkage on cooling, degradation in the canal, and inability to reinforce the root canal. ${ }^{1-5}$

Endodontics becomes a challenge when the clinician encounters a tooth with an open apex. An open apex is a normal physiological phenomenon observed during radicular development of teeth. Thereafter, two-and-half to three years after the eruption, the apical closure of the teeth takes place. ${ }^{6-8}$ The stages of root ontogenesis have been described by various authors such as Nolla, Moorrrees, Cvek, and Andreasen. ${ }^{9-11}$ Apical constriction or the width of apical foramen greater than $1 \mathrm{~mm}$ qualifies the entity to be christened open apex. Incomplete root formation usually stems from the pulpal necrosis resulting from the sequelae of dental caries or frontal trauma. ${ }^{6-8}$

Traditionally, there are two variants of open apices: one is of blunderbuss and the other is nonblunderbuss type of morphology. In the blunderbuss variant, the radicular walls are divaricated and flared out, the apical third is distinctively wider than at the coronal aspect, it characteristically is funnel-shaped. In the nonblunderbuss apex, the internal dentinal walls of the root canal are moderately convergent or exhibit parallelism. ${ }^{6-8}$
${ }^{1}$ Conservative Dentistry and Endodontics, Army Dental Centre, Research and Referral, Delhi, India

${ }^{2}$ General Dental Services, IHQ of MOD (Army), Delhi, India

${ }^{3,4}$ Conservative Dentistry and Endodontics, AB Shetty Memorial Institute of Dental Sciences, Delhi, India

Corresponding Author: Sonali Sharma, Conservative Dentistry and Endodontics, Army Dental Centre, Research and Referral, Delhi, India, Phone: +91 9717888513, e-mail: sonaliendo@gmail.com

How to cite this article: Sharma S, Londhe SM, Hegde MN, et al. Are Bioceramics the Dernier Cri in the Management of Stage 4 Developed Root? A Finite Element Analysis. J Contemp Dent Pract 2020;21(9): 961-969.

Source of support: KS Institute of Technology for the Finite Element Analysis

Conflict of interest: None

Cvek gave a comprehensive classification of incomplete rhizogenesis. Stage 5 is when the tooth has matured and the apical closure is achieved. Stage 1 to stage 3 are when, in varying stages, the longitudinal growth of the root is incomplete. Stage 4 is when the longitudinal development of the root is completed but the apical configuration may still have open apices (Fig. 1). ${ }^{11}$ Thus, the selection of the treatment protocol for an affected tooth is dictated by the stage of root development and the vitality status. For stage $1-3$, treatment protocols, depending on the pulpal status, range from apexogenesis, apexification, or regenerative endodontic. 


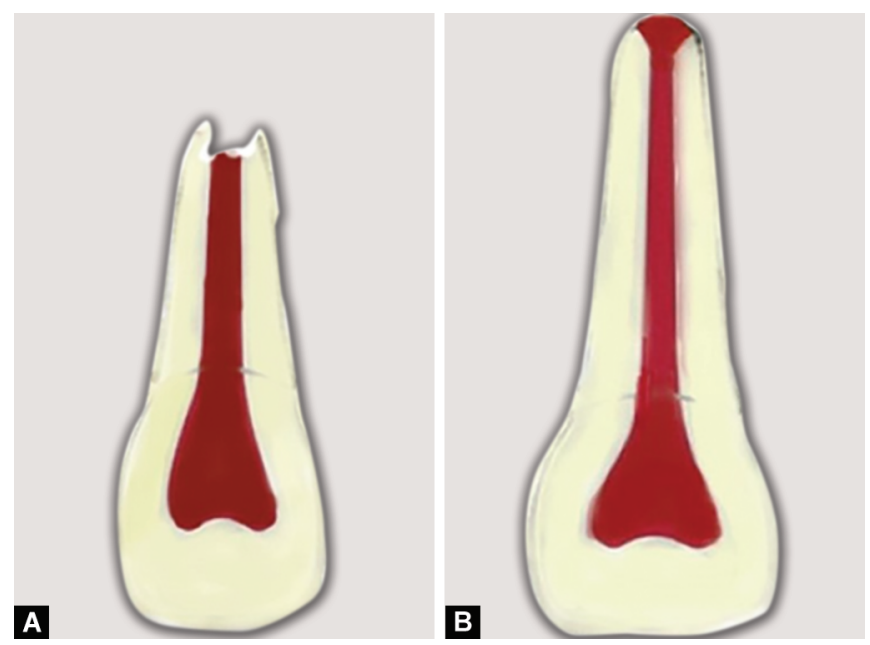

Figs 1 A and B: Open apex stages: (A) Stage 3-incomplete longitudinal growth of root; (B) Stage 4-incomplete closure of root apices with completed root length

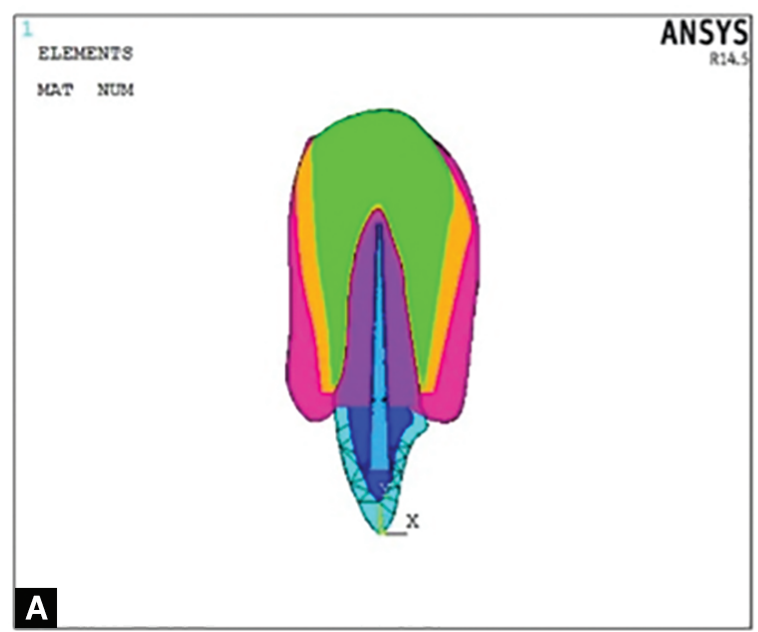

Figs 2A and B: (A) Model build-up is done; (B) Meshing is done

Plascencia et al. have compared different management protocols for necrotic teeth, correlating it with the stage of development. The treatment advocated for stage 4 was apexification with calcium hydroxide or obturation with gutta-percha with or without sans, a plug of $\mathrm{Ca}(\mathrm{OH})_{2}{ }^{11,12}$ Andreasen et al., on the contrary, have observed long-term placement of calcium hydroxide intraradicularly, which will result in a debilitative apical third. ${ }^{13}$ Thus, specifically for Stage 4, management strategies need to be further reviewed.

For the management of immature nonvital teeth, various biomaterials have been compared and contrasted: calcium hydroxide, MTA, Bioaggregate, and Biodentine have all shown to be successful with variable amplitude. ${ }^{14-27}$ Studies have shown that obturation with gutta-percha or resilon was unable to reinforce the immature teeth to oblique forces. Osiri et al. has observed that prepared weakened roots obturated with calcium silicatebased sealer and modified gutta-percha cone had reinforced the roots, and the recorded fracture resistance was comparable to that of intact nonaffected roots. ${ }^{25}$ Camilleri has advocated the use of hydraulic calcium silicates or the second generation of these
Table 1: Overview of material properties-the modulus of elasticity and the Poisson's ratio of each material are enumerated

\begin{tabular}{lcl}
\hline & \multicolumn{2}{c}{ Material properties } \\
\cline { 2 - 3 } Description & $\begin{array}{l}\text { Modulus of } \\
\text { elasticity (GPA) }\end{array}$ & Poisson's ratio \\
\hline Enamel & 41 & 0.33 \\
Dentin & 18.6 & 0.31 \\
Pulp & $0.23 \times 10^{-7}$ & 0.3 \\
Periodontal liagament & $68.93-3$ & 0.45 \\
Cortical bone & 13.7 & 0.3 \\
Cancellous bone & 1.37 & 0.3 \\
Gingiva & $19.6 \times 10^{-3}$ & 0.3 \\
Bioaggregate & 26 & 0.25 \\
Ceramicrete & 15 & 0.92 \\
Biomimetic mineralization & 18.6 & 0.31 \\
Biodentine & 22 & 0.30 \\
Bonding system [clearfil SE bond] & 0.56 & 0.25 \\
Composite core & 12 & 9.3 \\
\hline
\end{tabular}

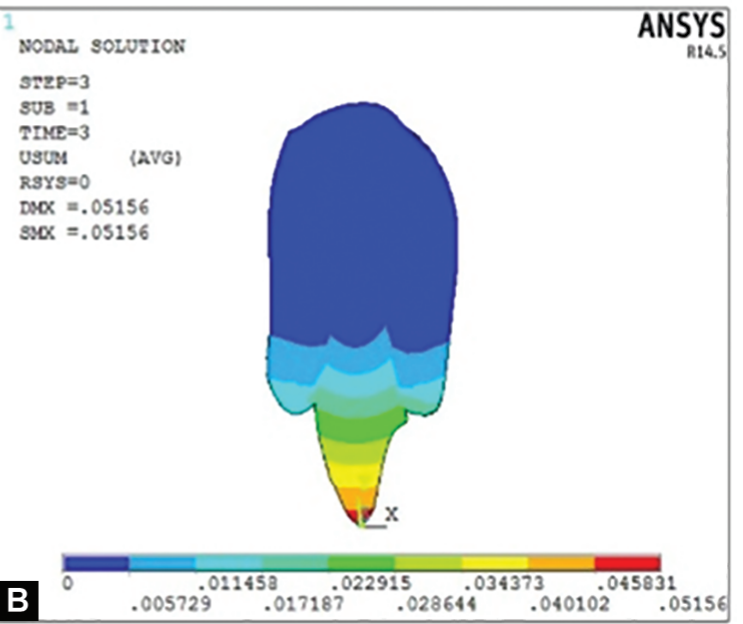

cements for root canal fillings in all clinical scenarios, especially immature necrotic teeth. ${ }^{27}$

Thus, this finite element study was designed to compare the stress distribution of stage 4 root development under various loading conditions, reinforced with Bioaggregate, bioceramics, Ceramicrete, and dentin coagulum-induced biomimetic remineralization. The loading conditions applied simulated conditions of mastication, horizontal frontal trauma, and bruxism.

\section{Materials and Methods}

A model of a central incisor with a stage 4 root development along with attachment apparatus was designed based on the physical and material properties obtained from published data (Table 1 and Fig. 2A). ${ }^{28-32}$ The tooth model which was computer-simulated based on the material properties was made up of small elements which are joined at points called nodes. Once the model was constructed, boundary conditions were made so that when stress was applied, the body under analysis was contained, hence meshing was done (Fig. 2B). All constituents of the anatomical model were isotropic; however, 
resinous materials were regarded as orthotropic, as they displayed divergent mechanical properties along the fiber direction ( $x$-direction) and with the other two remaining directions ( $y$ - and $z$-direction).

Four different models were developed, and each model was constituted of elements: 315807 and nodes: 53900 (Fig. 2).

Model 1: Nonvital central incisor with stage 4 developed root, as per Cvek classification, managed with the Ceramicrete obturation to replicate a primary monoblock and the access cavity restored with a composite definitive restoration (access filling).

Model 2: Nonvital central incisor with stage 4 developed root, as per Cvek classification, managed with the primary replacement material, a product of biomimetic mineralization strategy with dentin coagulum, which resulted in dentin-like material of 18.6 GPa modulus of elasticity and the access cavity restored with a composite definitive restoration (access filling).

Model 3: Nonvital central incisor with stage 4 developed root, as per Cvek classification, managed with Biodentine obturation to replicate a primary monoblock, and the access cavity restored with a composite definitive restoration (access filling).

Model 4: Nonvital central incisor with stage 4 developed root, as per Cvek classification, managed with Bioaggregate obturation to replicate a primary monoblock, and the access cavity restored with a composite definitive restoration (access filling).

Each model was meshed to prevent displacement and set boundary conditions and then subjected to three different loading conditions 6 months after restoration.

- To reproduce masticatory forces at $45^{\circ}$, a $70 \mathrm{~N}$ inclined load was applied to central incisors.

- To mimic bruxism, a $100 \mathrm{~N}$ load was applied on the incisal edge of central incisors.

- To mimic the horizontal frontal trauma, a $100 \mathrm{~N}$ horizontal load has collided labially on the central incisor crown.

Finite element analysis (FEA) software ANSYS was used to analyze the distribution stresses. These stresses are an agglomeration of tensile, compressive, tension, shear stress known as von Mises stresses. It is a failure criterion experimented on ductile substances. von Mises stresses relies on the consolidated and condensed stress range and is extensively used to predict the probability of catastrophic failure.

\section{Results}

- To simulate mastication, a load of $70 \mathrm{~N}$ at 45 -degree inclination was targeted on the restored central incisor.

Model 1: It was observed that the stresses were concentrated on the labial cervical neck of the tooth. Stress concentration was also observed at the junction of coronal and middle third of the root, but it was observed only on the labial surface. The stresses which were transmitted to the periapex through the root and surrounding apparatus prevented stress concentration at the apex (Fig. 3A). The stress concentration on the replacement monoblock material was seen at the junction of the coronal and middle third (Fig. 3). When stress distribution was evaluated on the dentin, it was found that maximum stress was concentrated labially at the junction of the coronal and middle third, corresponding to that of the replacement material (Fig. 3C). The stress was also transmitted to the periodontium at the coronal third (Fig. 3D).

Model 2 was subjected to a $70 \mathrm{~N}$ load at an angle of $45^{\circ}$ to simulate mastication. The replacement material was a byproduct of biomimetic mineralization induced by dentin coagulum. The final primary monoblock was dentin-like material. The locus of the maximum stress was akin to that of Model 1, but the eminence was of a less degree and comparably the transmission to dentin was less (Fig. 3). The reinforcement material had slightly more stress than Model 1 and even transmission to periodontium was more (Figs $3 \mathrm{~A}$ and D).

Model 3 was likewise subjected to $70 \mathrm{~N}$ of an inclined load to simulate mastication. It was rehabilitated with Biodentine as an obturating material. The total sectional forces were less than Models 1 and 4 (Fig. 3A). The stress concentration on the replacement monoblock material was seen at the junction of the coronal and middle third (Fig. 3B). When stress distribution was evaluated on the dentin, it was found that maximum stress was concentrated labially at the junction of the coronal and middle third, corresponding to that of the replacement material (Fig. 3C). The stress was also transmitted to the periodontium at the coronal third (Fig. 3D). The location of maximum forces is the same as in Models 1 and 4, in the replacement material, in the dentin, and in the periodontium. But the amount or magnitude is less (Fig. 3).

Model 4 was rehabilitated with Bioaggregate when it was targeted with a load of $70 \mathrm{~N}$ at $45^{\circ}$; it was observed that the total sectional forces were marginally less than Model 3 but more than Model 1 (Fig. 3A). The stress concentration on the replacement monoblock material was seen at the junction of the coronal and middle third (Fig. 3B). When stress distribution was evaluated on the dentin, it was found that the maximum stress was concentrated labially at the junction of the coronal and middle third, corresponding to that of the replacement material (Fig. 3C). The stress was also transmitted to the periodontium at the coronal third (Fig. 3D). The location of maximum forces is the same as in other models, in the replacement material, in the dentin, and in the periodontium, but the amount or magnitude is less than model 1 (Fig. 3).

- To simulate bruxism, a vertical load of $100 \mathrm{~N}$ was levelled at the incisal edge of the central incisors: The sectional sections of all the models of different modulus of elasticity exhibited an identical quantum of stresses, but the replacement materials had an expanding stress value from Model 1 to Model 4 sequentially, right from the coronal third of the replacement cone, traversing through the middle third and with high level of stress level in open apices (Figs 4A and B). The surrounding dentin had lower stress values in Model 2 as compared to Model 1; thereafter, there was an increase in values from Model 3 to Model 4 (Fig. 4C). The transmission of forces to the periodontium is of extremely high magnitude from the crestal region to the mid-root level, and Model 2 had lower values than that of Model 1 and Model 3 had lower values than Model 4 (Fig. 4D).

- To mimic the impact of horizontal forces of a frontal impact, a load of $\mathbf{1 0 0} \mathbf{N}$ was applied labially: The stresses were mainly concentrated in the radicular middle third of both buccal and palatal surfaces and analogously on the buccal and palatal surfaces at the crown root constriction at the neck of crown (Fig. 5A). The replacement materials have the maximum stress concentrated on the coronal level and then again a high concentration of stress is seen extending from the middle third to the apical third region of the root. There is a marked increase in the magnitude of the stress increased from Model 1 to Model 4 (Fig. 5B). In the dentin for all models, the concentration of stress 


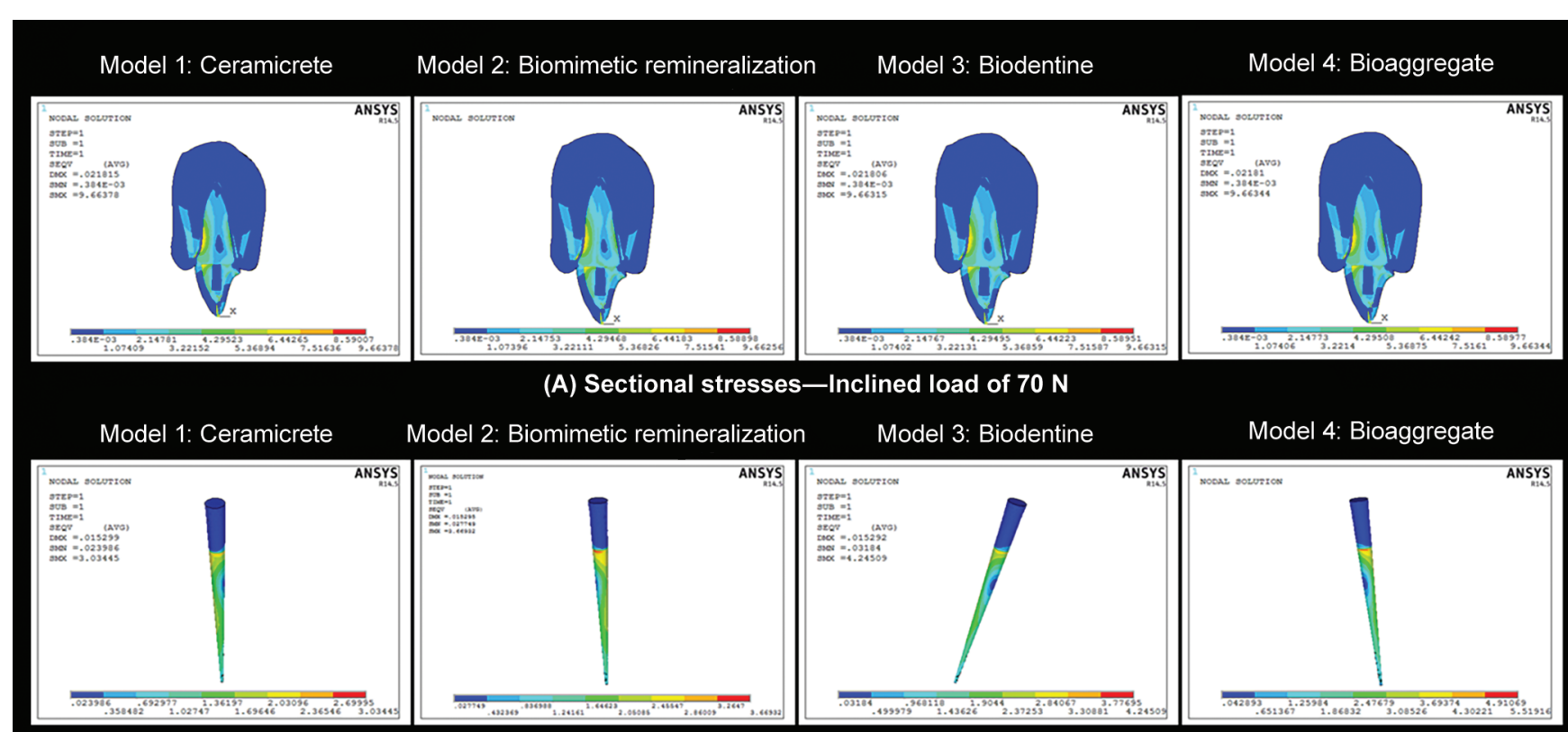

(B) Reinforcing replacement materials-Inclined load of $70 \mathrm{~N}$

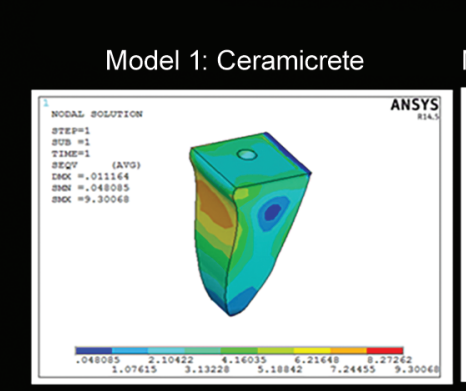

Model 2: Biomimetic remineralization
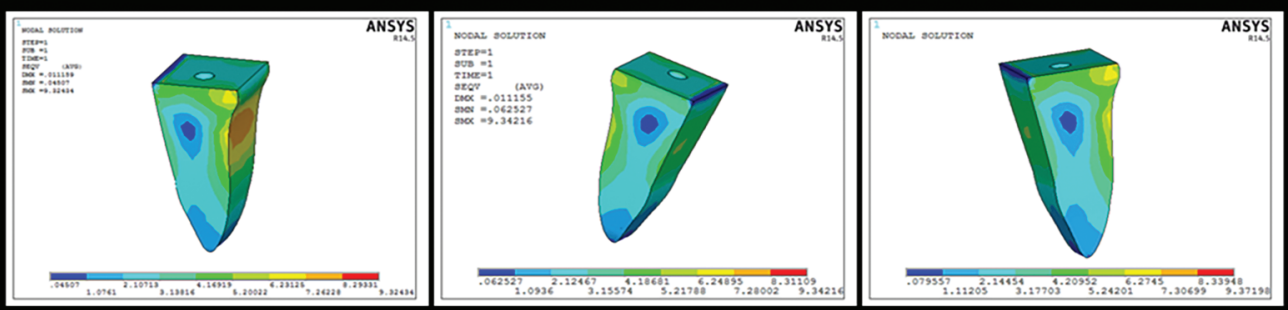

(C) Dentin-Inclined load of $70 \mathrm{~N}$

Model 1: Ceramicrete Model 2: Biomimetic remineralization

Model 3: Biodentine

Model 4: Bioaggregate
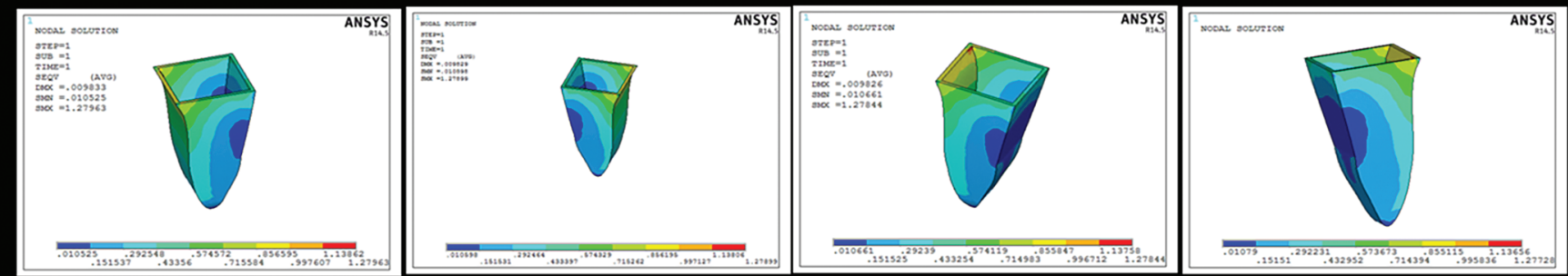

(D) Periodontium-Inclined load of $70 \mathrm{~N}$

Figs 3A to D: Stress analysis of loading conditions of $70 \mathrm{~N}$ inclined load: (A) Maximum stress concentration on the tooth was concentrated on the middle third of the labial surface. Maximal stresses observed in Model 1 then in Models 4, 3, and least in 2; (B) Obturating material stresses increased from Model 1 to 4; (C) Dentin stresses increased from Model 1 to 4; (D) Stresses transmitted to periodontium decreased from Model 1 to 4

is marked in the middle third (Fig. 5C). There is a pronounced increase in stress values on the crestal level of the periodontium (Fig. 5D).

To summarize the results, during mastication, it was observed that the stresses were concentrated on the labial cervical neck of the tooth. Stress concentration was also observed at the junction of coronal and middle third of the root, but it was observed only on the labial surface. Maximum stress values observed in Model 1: Ceramicrete followed by Model 4: Bioaggregate group; Model 3: Biodentine; Model 2; dental coagulum-induced biomimetic mineralization, in descending order.

For the loading forces simulating bruxism, it was observed that all the models exhibited a resemblant amount of forces on the incisal edge. Stresses on obturating material increased from Model 1 to Model 4 to Model 2 to Model 3. The difference between the magnitude of stress between Model 4 and Model 2 is minuscule. The stress concentration in dentin decreased from Model 1 to Model 4. Stresses transmitted to periodontium decreased from Model 1 to Model 4. 


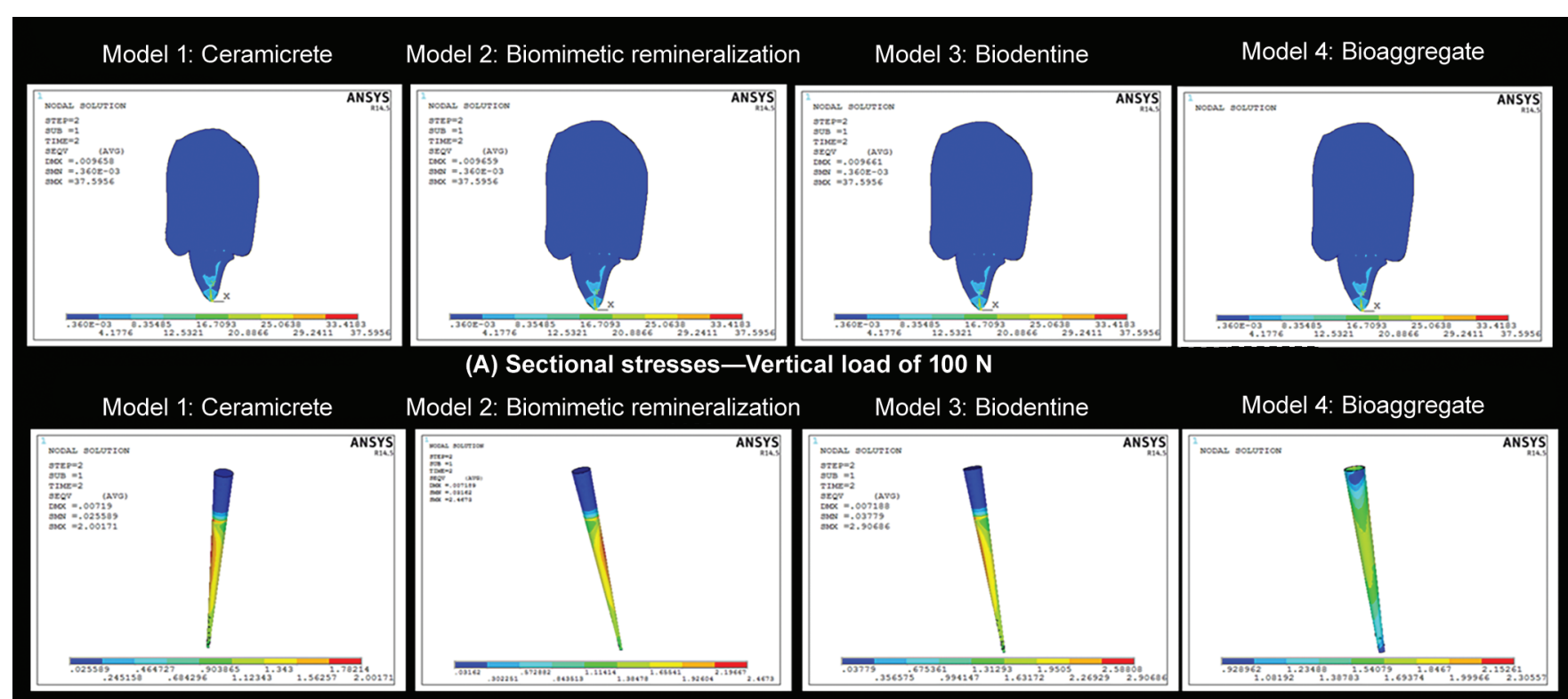

(B) Reinforcing replacement materials-Vertical load of $100 \mathrm{~N}$

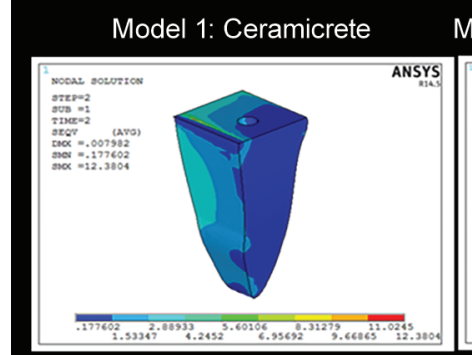

Model 2: Biomimetic remineralization
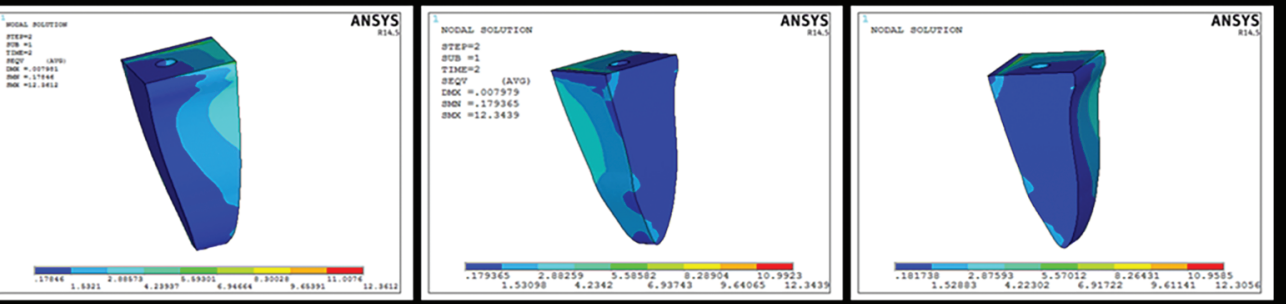

(C) Dentin-Vertical load of $100 \mathrm{~N}$

Model 1: Ceramicrete Model 2: Biomimetic remineralization

Model 3: Biodentine

Model 4: Bioaggregate
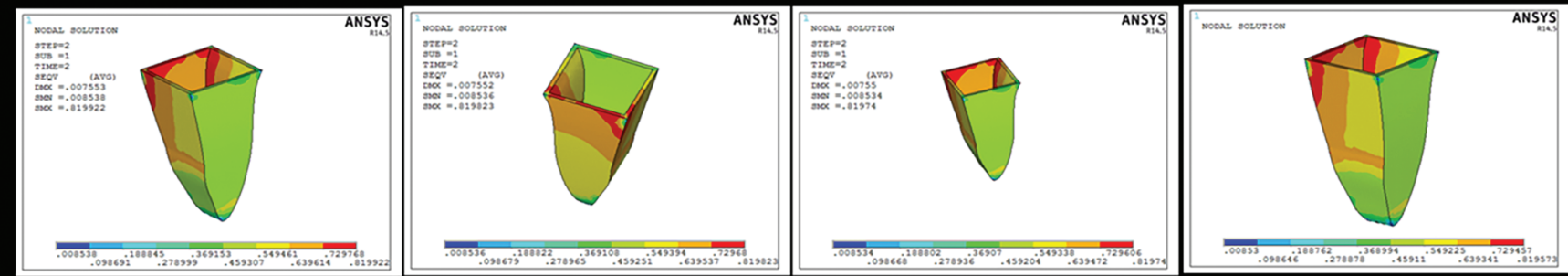

(D) Periodontium-Vertical load of $100 \mathrm{~N}$

Figs 4A to D: Stress analysis of loading conditions of $100 \mathrm{~N}$ vertical load: (A) Stress magnitude was same for each group and was concentrated on incisal edge; (B) Stresses on obturating material increased from Model 1 to Model 4 to Model 2 to Model 3; (C) Stress concentration in dentin decreased from Model 1 to 4; (D) Stresses transmitted to periodontium decreased from Model 1 to 4

In cases of frontal trauma, it was observed that stresses were mainly concentrated in the radicular middle third of both buccal and palatal surfaces and consistently on the buccal and palatal surfaces at the neck of the crown. The magnitude of the stress increased from Model 1 to Model 4.

\section{Discussion}

Biomimicry or biomimetics is the mirroring or echoing of substances and systems to enable or provide the solution of complications, deadlocks, or insurmountable problems which plague the Homo sapiens. In endodontics, we all know that the best replacement for pulp is a vital pulp. We are in the mid of decoding the ideal pulp dentin complex algorithm. Till we do so, the search for an ideal substitute for necrotic pulpal which will serve as a primary endodontic replacement monoblock is ON. The material which would seem to be ideal should be bioinert, biodegradable, and at the same time, bioactive also. Reams of paper have been added to the literature on the management of immature teeth with divergent open apex. The management strategy of stage 3 of root 


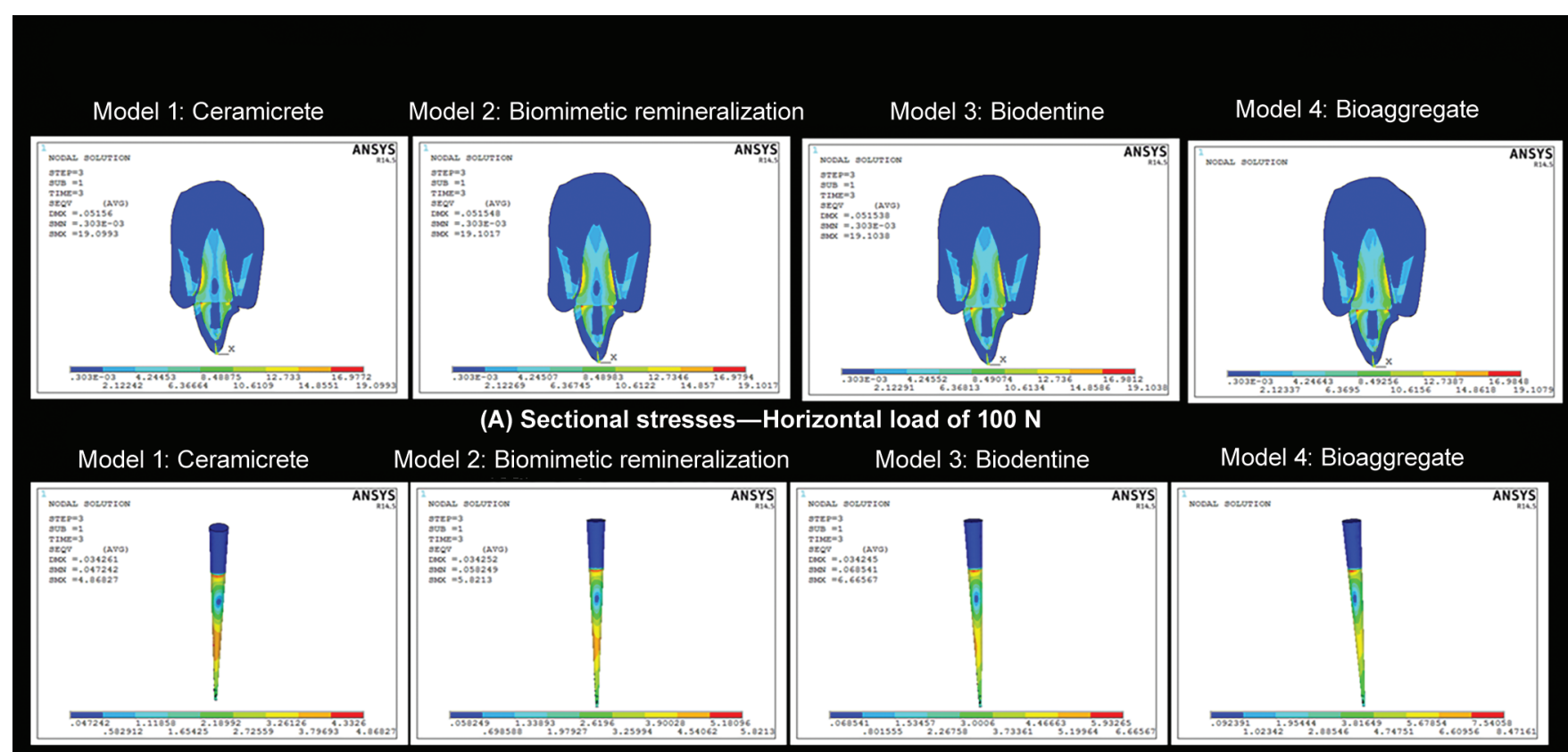

(B) Reinforcing replacement materials-Horizontal load of $100 \mathrm{~N}$

Model 1: Ceramicrete

Model 2: Biomimetic remineralization

Model 3: Biodentine

Model 4: Bioaggregate
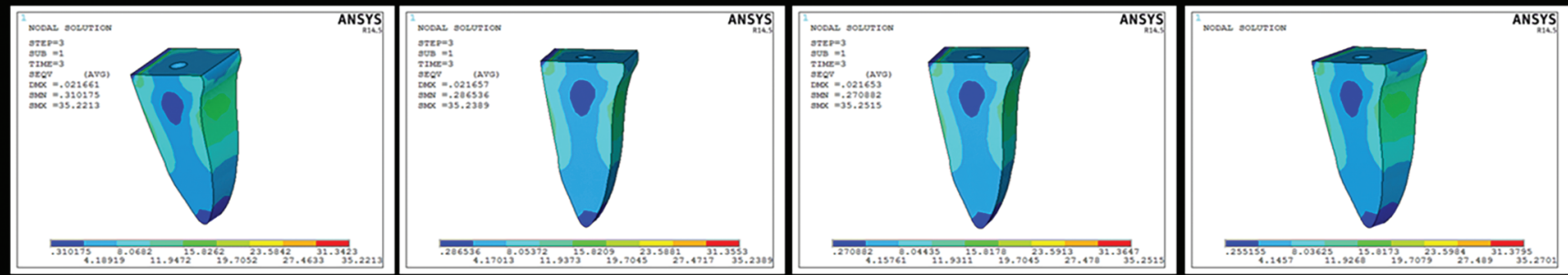

(C) Dentin-Horizontal load of $100 \mathrm{~N}$

Model 1: Ceramicrete Model 2: Biomimetic remineralization

Model 3: Biodentine

Model 4: Bioaggregate
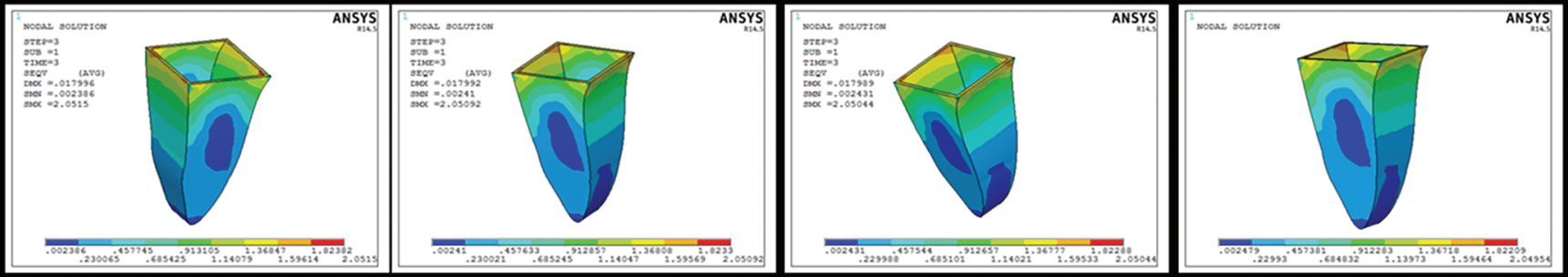

(D) Periodontium-Horizontal load of $100 \mathrm{~N}$

Figs $5 \mathrm{~A}$ to $\mathrm{D}$ : Stress analysis of loading conditions of $100 \mathrm{~N}$ horizontal impact: (A) Stresses were concentrated in the radicular middle third and neck of the crown on both buccal and palatal surfaces. The magnitude of the stress increased from Model 1 to 4 ; (B) Stresses on obturating material increased markedly from Model 1 to 4; (C) Stress concentration in dentin increased from Model 1 to 4; (D) Stresses transmitted to periodontium increased from Model 4 to 1

development has ranged from induced and guided apexogenesis, apexification, revitalization, and regenerative endodontics. ${ }^{33-38}$ But for stage 4 with an incomplete apical closure with an increase in endodontic width, no guidelines have been documented. Hence, in this study, the clinical scenario, which was the population sample, was stage 4 of root development.

The challenge with an open apex of a nearly mature tooth is the placement of apical closure-inductive material till the periapex through a tapering canal. Further, a gutta-percha cone base has a different modulus of elasticity than the material used for apical closure. The apical seal of a traditionally obturated root canal is questionable, especially when the apices are open and wide. ${ }^{21}$ Traditionally, calcium hydroxide was used to induce apical closure, the time taken for induction of an apical bridge was timeconsuming and further the continuous intracanal replenishment leads to $50 \%$ chance of weakening the apical dentin. ${ }^{39}$ Bioceramics has been used for inducing apical closure. ${ }^{40-42}$ MTA has shown promising results in maintaining an impervious apical seal. ${ }^{43}$ Calcium silicate materials whether of generation one or the newer generation are bioinert, bioactive, and biodegradable. ${ }^{44}$ Hence, 
this study was designed to compare different bioactive calcium silicate-based materials for replacing the pulp in a central incisor with a stage 4 root development.

Mente et al. have conducted the long-term study of managing immature teeth with an MTA plug with favorable predictable outcomes. ${ }^{45}$ MTA has certain limitations, such as high cost, poor handling properties, long setting time, and toxic constituents in its formulation, difficulty in case of revisionism. Biodentine is a calcium silicate-based formulation almost identical to MTA with improved physical properties, handling, and reduced setting time. ${ }^{44,46}$ The advantage of using Biodentine is that it has a modulus of elasticity of $22 \mathrm{GPa}$ which is comparable to that of dentin, $18.6 \mathrm{GPa} .{ }^{44,46} \mathrm{Hence}$, in this study, it was the replacement material in Model 3.

Argonne National Laboratory, USA, has developed a material called Ceramicrete. It is a byproduct of an acid-base reaction between the acid of potassium hydrogen phosphate and the base which is calcined magnesium oxide. This reaction produces a binder which will be mixed with aggregate and water to form a concrete-like material. The Ceramicrete-based material, which is being investigated for dental applications, is lightweight, with an accelerated setting time of 6 minutes of initial set and a final set of 12 minutes, and elevated compressive strength. The advantage is that it can be furled akin to putty and can be easily manipulated with dental hand instruments. Additionally, it can set in the presence of water without a washout. ${ }^{46,47}$ Leal et al. have compared the white MTA, Ceramicrete D, and Bioaggregate, all three exhibited comparable leakage results. ${ }^{48}$ Ceramicrete showed superior properties to MTA in terms of setting, handling, and washout; however, it had lower compressive strength and less radiopacity. ${ }^{46}$ The Model 1 was constituted with the replacement monoblock of Ceramicrete.

Zhang et al. in a path-breaking study demonstrated to obturate a root canal with a biomimetic mineralizing primary endodontic monoblock. It was observed that there was an exponential interlacing of hydroxyapatite crystal into the dentinal tubules. ${ }^{49}$ Hence, in this study for Model 2, a replacement material composed of a biomimetic mineralized tissue of modulus of elasticity of 18.6 GPa, comparable to that of dentin, was investigated. The mineralized tissue resembled dentin and was a byproduct of the mineralization of dentin coagulum of which the empty canal was filled with.

Bioaggregate (Verio Dental Co. Ltd., Vancouver, Canada) is a calcium silicate cement which comprises nanomicelles of calcium phosphate, tricalcium silicate, silicon dioxide, and tantalum oxide. ${ }^{46}$ Compared to MTA, the Bioaggregate cement does not have aluminum as a constituent. Further, it shows an early release of calcium ions as opposed to MTA. Though the reactivity of aggregate is less than MTA, it is more biocompatible, has acid, and has higher fracture resistance and better sealing ability. The induction of osteoblastic differentiation and mineralization potential is much higher with Bioaggregate. ${ }^{46,50-52}$ Hence, in this study, the rehabilitation of the pulpal space of Model 4 was done with Bioaggregate. The modulus of elasticity of Bioaggregate was $26 \mathrm{GPa}$.

As given in a classical study, ${ }^{28}$ the concept of endodontic replacement monoblocks was incorporated in this study. The endodontic replacement monoblocks can be either primary, secondary, or tertiary. ${ }^{28}$ Studies have shown that as more and more interfaces such as cement, sealers, bonding agents are added, the very goal of forming a monoblock is defeated. This could be because all these materials which have a different range of moduli of elasticity will flex at different magnitude disproportionate to that of dentin. ${ }^{28-32}$ The replacement materials which were used in this study were primary monoblocks with the modulus of elasticity as $15,18.6,22$, and $26 \mathrm{GPa}$. They were primary monoblocks without any other interface between them and the dentinal surface of the root. Circumstances and settings of primary endodontic replacement monoblocks were mirrored, and the materials which were more commonly used for apical closure were used as rehabilitating obturation materials for a central incisor with a stage 4 root development.

The effect of these materials on the tooth structure and their efficacy in deflecting or distributing stress without any catastrophic failures need a method of analysis which can be validated. Most of the methods which were utilized in the past relied only on surface analysis. The methodology which can comprehensively analyze three-dimensionally and predict excessive stress in a particular region of the body under study is called finite element analysis. It is thus a noninvasive method in which, based on the physical properties of the material, a computer-based model is created and it is then meshed to delineate a boundary and then subjected to various loading conditions. By this analysis, one can predict at which point or area the failure will occur by studying the agglomeration of stresses, called von Mises stresses. In this study, the physical properties of the material-like modulus of elasticity and Poisson ratio were noted for model buildup from the classical study by Pegoretti, ${ }^{29}$ studies by Sharma et al., ${ }^{30-32}$ and other finite element analysis studies. ${ }^{38,53,54}$

Studies by Eram and Bayram et al. have compared the fracture resistance of immature teeth rehabilitated with MTA, Biodentine, and Bioaggregate. ${ }^{38,55}$ The study by Bayram concluded that all three materials were successful in reinforcing the tooth. In this study, we have evaluated the effect of materials such as Ceramicrete, mineralization product of autogenous dentin coagulum, Biodentine, and Bioaggregate in reinforcing the internal root morphology. During mastication, it was observed that Ceramicrete group-Model 1 induced more stresses than the rest. The least amount of stress was induced by Model 2 of biomimetic mineralization group. Even the stresses transmitted to dentin increased from Model 1 to 4 , in tandem with an increasing modulus of elasticity. The transmission of forces to the periodontium was more with the Biodentine than with the Bioaggregate group. The Ceramicrete group had less transmission of forces to periodontium than the biomimetic mineralization group. During bruxism, all the groups exhibited almost identical stresses. But the evaluation of replacement materials showed Bioaggregate group exhibited less von Mises stresses as compared to Biodentine group. During a frontal collision, the Bioaggregate group exhibited larger magnitude of von Mises stresses and there was more transmission to the surrounding dentine and less transmission of forces to periodontium than Biodentine. The Ceramicrete group exhibited less stress than biomimetic mineralization group, which was less than dentine group. None of these materials showed any concentration at the root apex. As in the study by Eram, ${ }^{38}$ its is noted that with complete obturation with reinforcing material, there was concentration on the neck of the teeth; this was only on the labial surface in the cases of mastication and bruxers, but in cases simulating collision injury, it is concentrated both on labial and palatal surfaces and on the constriction of the neck of the teeth. 
In this study, we have filled the stage 4 developed root with dentin coagulum consistent to the study by Zhang ${ }^{52}$ with dentin coagulum and loaded it after 6 months to mimic three loading conditions of mastication, vertical trauma, and horizontal trauma. Since the modulus of elasticity of dentin was nearly identical to that of dentin coagulum-derived mineralized material rehabilitating Model 2, the magnitude of stresses was much less than that of Bioaggregate and Biodentine and Ceramicrete group under loading conditions of mastication. For vertical trauma and horizontal trauma, it was observed that Model 1 had the least amount of stresses followed by Model 2, Model 3, and Model 4. But the stress concentration pattern was more or less indistinguishable for all models for that particular loading condition.

There are certain limitations of finite element analysis. As it is a computer-generated study, the clinical conditions may always not be possible to accurately replicate. Further, the mechanical properties are considered as isotropic and in real-time are not linearly elastic and neither are loading conditions static. This study has incorporated in detail the various constituent of the tooth structure and the various materials used to rehabilitate it. Further, the composite material in access cavity restoration is not considered isotropic, and hence, as far as possible a realistic model has been computer-generated. The challenge, however, was in Model 2, in which dentin coagulum was placed in the root canal, and after 6 months of biomimetic, it was hypothesized to have been filled with a calcific material like that of dentin. In reality, the complete in situ deposition of the calcific material is not uniform, which could not be intrinsically replicated.

It can be summarized that for reinforcing the radicular space in a case of stage 4 root development, the outcomes of the various models and their loading conditions were as Model 2 had the modulus of elasticity equivalent to that of dentin, it had the least magnitude of stress during mastication. Biodentine came a close second followed by Bioaggregate. The new material Ceramicrete had the greatest level of stresses. But the transmission of forces to dentin was increasing with an increasing modulus of elasticity. This phenomenon was seen under all loading conditions. The stress levels were the same during bruxism for all models. During frontal trauma, there was increasing stress level corresponding to an increase in the modulus of elasticity.

\section{Conclusion}

Within the limitation of the study, it can be concluded that as the modulus of elasticity of the reinforcing material deviates from that of dentin, the magnitude of stress increases. However, as the increase in stress values was minimal between groups, all these materials can serve as primary replacement monoblocks. Biomimetic mineralization strategies can be a viable treatment option for managing cases of the open apex. These materials can all serve as clinically viable primary replacement endodontic monoblocks in cases of open apices.

\section{Acknowledgment}

Mr M Nagabhushana, Associate Professor, KS Institute of Technology for the Finite Element Analysis.

\section{References}

1. Grossman LI, Oliet S, Del Rio CE. Endodontic Practice. The University of Michigan: Lea \& Febiger; 1988.
2. Whitworth J. Methods of filling root canals: principles and practices Endod Topics 2005;12(1):2-24. DOI: 10.1111/j.1601-1546.2005.00198.x.

3. Schilder H. Filling root canals in three dimensions. Dent Clin North Am 1967;11(7):723-744.

4. Hülsmann M, Peters OA, Dummer PMH. Mechanical preparation of root canals: shaping goals, techniques and means. Endodontic Topics 2005;10(1):30-76. DOI: 10.1111/j.1601-1546.2005.00152.x.

5. Ribeiro FC, Souza-Gabriel AE, Marchesan MA, et al. Influence of different endodontic filling materials on root fracture susceptibility. J Dent 2008;36(1):69-73. DOI: 10.1016/j.jdent.2007.10.007.

6. Smyth R, Philpott B. Management of the open apex in endodontics: current techniques and new solutions when dealing with the open apex in root canal surgery. Scottish Dental Magazine 2017:7.

7. Vier FV, Figueredo JAP. Prevalence of different periapical lesions associated with human teeth and their correlation with the presence and extension of apical external root resorption. Int Endod J 2002;35(8):710-719. DOI: 10.1046/j.1365-2591.2002.00554.x.

8. Gutmann JL, Heaton JF. Management of the open (immature) apex. Vital teeth Int Endodon J 1981;14(3):166-172. DOI: 10.1111/j.13652591.1981.tb01082.x.

9. Nolla CM. The development of the permanent teeth. J Dent Child 1960;27:254-266.

10. Moorrees CFA, Fanning EA, Hunt EE. Age variation of formation for ten permanent teeth. J Dent Res 1963;42(6):1490-1502. DOI: 10.1177/00220345630420062701.

11. Plascencia H, Diaz M, Gascon G, et al. Management of permanent teeth with necrotic pulps and open apices according to the stage of root development. J Clin Exp Dent 2017;9(11):e1329-e1339. DOI: 10.4317/jced.54287.

12. Rafter M. Apexification: a review. Dent Traumatol 2005;21(1):1-8. DOI: 10.1111/j.1600-9657.2004.00284.x.

13. Andreasen JO, Farik B, Munksgaard EC. Long-term calcium hydroxide as a root canal may increase risk of root fracture. Dent Traumatol 2002;18(3):134-137. DOI: 10.1034/j.1600-9657.2002.00097.x.

14. Torabinejad M, Corr R, Buhrley M, et al. An animal model to study regenerative endodontics. J Endod 2011;37(2):197-202. DOI: 10.1016/j. joen.2010.10.011.

15. Hench L. Bioceramics. J Am Ceram Soc 1998;8(7):1705-1728. DOI: 10.1111/j.1151-2916.1998.tb02540.x.

16. Best SM, Porter AE, Thian ES, et al. Bioceramics: past, present and for the future. J Euro Ceram Soc 2008;28(7):1319-1327. DOI: 10.1016/j. jeurceramsoc.2007.12.001.

17. Haapasalo $M$, Parhar $M$, Huang $X$, et al. Clinical use of bioceramic materials. Endod Topics 2015;32(1):97-117. DOI: 10.1111/etp. 12078.

18. Shen $Y$, Peng $B$, Yang $Y$, et al. What do different tests tell about the mechanical and biological properties of bioceramic materials? Endod Topics 2015;32(1):47-85. DOI: 10.1111/etp.12076.

19. El-Meligly OA, Avery DR. Comparison of apexification with mineral trioxide aggregate and calcium hydroxide. Pediatr Dent 2006;28:248253.

20. Witherspoon DE, Small JC, Regan JD, et al. Retrospective analysis of open apex teeth obturated with mineral trioxide aggregate. J Endod 2008;34(10):1171-1176. DOI: 10.1016/j.joen.2008.07.005.

21. Andreasen JO, Munksgaard EC, Bakland LK. Comparison of fracture resistance in root canals of immature sheep teeth after filling with calcium hydroxide or MTA. Dent Traumatol 2006;22(3):154-156. DOI: 10.1111/j.1600-9657.2006.00419.x.

22. Desai $S$, Nicholas $C$. The restoration of permanent immature anterior teeth, root filled using MTA: a review. J Dent 2009;37(9):652-657. DOI: 10.1016/j.jdent.2009.05.026.

23. Mehmet B, Ekçi ES, Odaba ME. Efficacy of biodentine as an apical plug in Nonvital permanent teeth with open apices: an in vitro study. Bio Med Res Int 2015;2015:359275.

24. Tuna EB, Dinçol ME, Gençay K, et al. Fracture resistance of immature teeth filled with Bioaggregate, mineral trioxide aggregate and calcium hydroxide. Dent Traumatol 2011;27(3):174-178. DOI: 10.1111/j.1600-9657.2011.00995.x. 
25. Osiri S, Banomyong D, Sattabanasuk V, et al. Root reinforcement after obturation with calcium silicate-based sealer and Modified gutta-percha cone. J Endod 2018;44(12):1843-1848. DOI: 10.1016/j. joen.2018.08.011.

26. Argueta JO. BioRoot ${ }^{\mathrm{TM}} \mathrm{RCS}$, a reliable bioceramic material for root canal obturation. Case Studies 2017;15(54):4-8.

27. Camilleri J. Will bioceramics be the future root canal filling materials. Curr Oral Health Rep 2017;4:228-238.

28. Tay FR, Pashley DH. Monoblocks in root canals: a hypothetical or a tangible goal. J Endod 2007;33(4):391-398. DOI: 10.1016/j. joen.2006.10.009.

29. Pegoretti A, Fambri L, Zappini G, et al. Finite element analysis of a glass fibre reinforced composite endodontic post. Biomaterials 2002;23(13):2667-2682. DOI: 10.1016/s0142-9612(01)00407-0.

30. Sharma S, Shashikala K. Cast metal post versus fiber post- A 3-dimensional finite element analysis. RGUHS-J Dent Sci 2008;1(2):1-8.

31. Sharma $S$. The viability of current obturating systems as replacement endodontic monoblocks - A 3 dimensional finite element analysis. Endodontol 2014;26(2):295-300.

32. Sonali S, Gupta SH, Anita K. A 3D finite element analysis to evaluate endodontic monoblocks. J Dent Def Sec 2014;9(2):13:19.

33. Andreassen JO, Andreassen FM. Essentials of Traumatic Injuries to the Teeth. Copenhagen: Munksgaard; 1994. p. 168.

34. Ham JW, Patterson SS, Mitchell DF. Induced apical closure of immature pulpless teeth in monkeys. Oral Surg, Oral Med, Oral Pathol 1972;33(3):438-449. DOI: 10.1016/0030-4220(72)90474-4.

35. Albadri S, Chau YS, Jarad F. The use of mineral trioxide aggregate to achieve root-end closure: three case reports. Dent Traumatol 2013;29(6):469-473. DOI: 10.1111/j.1600-9657.2012.01128.x.

36. Young CS, Terada $S$, Vacanti JP, et al. Tissue engineering of complex tooth structures on biodegradable polymer scaffolds. J Dent Res 2002;81(10):695-700. DOI: 10.1177/154405910208101008.

37. Kim SG, Malek M, Sigurdsson A, et al. Regenerative endodontics: a comprehensive review. Int Endod J 2018;51(12):1367-1388. DOI: 10.1111/iej.12954.

38. Eram A, Zuber M, Keni LG, et al. Finite element analysis of immature teeth filled with MTA, biodentine and bioaggregate. Comput Methods Programs Biomed 2020;190:105356. DOI: 10.1016/j. cmpb.2020.105356.

39. Raldi DP, Mello I, Habitante SM, et al. Treatment options for teeth with open apices and apical periodontitis. J Can Dent Assoc 2009;75(8):591-596.

40. Jain JK, Ajagannanavar SL, Jayasheel A, et al. Management of a fractured nonvital tooth with open apex using mineral trioxide aggregate as an apical plug. Int J Oral Health Sci 2017;7(1):44-47. DOI: 10.4103/ijohs.ijohs_17_17.

41. Rosaline H, Rajan M, Deivanayagam K, et al. Ferro-concrete reinforcement of endodontically treated teeth with wide open apex. Indian J Dent Res 2015;26(3):276-279. DOI: 10.4103/0970-9290. 162888.

42. Jaiswal S, Gupta S, Sawani S, et al. Bioactive closure of Non vital immature tooth with open apices.A contemporary approach. People's J Sci Res 2014;7(2):70-74.

43. Torabinejad M, Watson TF, Pitt Ford TR. Sealing ability of a mineral trioxide aggregate when used as a root end filling material. J Endod 1993;19(12):591-595. DOI: 10.1016/S0099-2399(06)80271-2.

44. Dawood AE, Parashos P, Wong RHK, Reynolds EC, Manton DJ. Calcium silicate-based cements: composition, properties, and clinical applications. J Investig Clin Dent 2017;8(2):1-15.

45. Mente J, Leo M, Panagidis D, et al. Treatment outcome of mineral trioxide aggregate in open apex teeth. J Endod 2013;39(1):20-26. DOI: 10.1016/j.joen.2012.10.007.

46. Raghavendra SS, Jadhav GR, Gathani KM, et al. Bioceramics in endodontics - a review. J Istanb Univ Fac Dent 2017;51(3 Suppl 1):S128-S137. DOI: 10.17096/jiufd.63659.

47. Mouring SE, Miller PH, Burns VL, Investigation into the Mechanical Behavior of Ceramicrete. Proceedings of The Thirteenth International Offshore and Polar Engineering Conference. May 25-30. 2003. Honolulu, Hawa2, USA.

48. Leal F, De-Deus G, Brandao C, et al. Comparison of the root-end seal provided by bioceramic repair cements and white MTA. Int Endod J 2011;44(7):662-668. DOI: 10.1111/j.1365-2591.2011.01871.x.

49. Zhang L, Li Q-L, Cao Y, et al. Regenerating a monoblock to obturate root canals via a mineralising strategy. Sci Rep 2018;8(1):13356. DOI: 10.1038/s41598-018-31643-8.

50. Camilleri J, Sorrentino F, Damidot D. Characterization of unhydrated and hydrated Bioaggregate and MTA angelus. Clin Oral Investig 2015;19(3):689-698. DOI: 10.1007/s00784-014-1292-4.

51. Tuloglu N, Bayrak S. Comparative evaluation of mineral trioxide aggregate and Bioaggregate as apical barrier material in traumatized nonvital, immature teeth: a clinical pilot study. Niger J Clin Pract 2016;19(1):52-57. DOI: 10.4103/1119-3077.164332.

52. Zhang S, Yang X, Fan M. Bioaggregate and iRoot BP plus optimize the proliferation and mineralization ability of human dental pulp cells. Int Endod J 2013;46(10):923-929. DOI: 10.1111/iej.12082.

53. Bucchi C, Marcé-Nogué J, Galler KM, et al. Biomechanical performance of an immature maxillary central incisor after revitalization: a finite element analysis. Int Endod J 2019;52(10):1508-1518. DOI: 10.1111/ iej.13159.

54. Ron AC, Karthik J, Pai VS, et al. Fracture resistance of simulated immature teeth rehabilitated with different restorative materials: a three-dimensional finite element analysis. Endodontol 2017; 29(1):11.

55. Bayram E, Bayram HM. Fracture resistance of immature teeth filled with mineral trioxide aggregate, bioaggregate, and biodentine. Eur J Dent 2016;10(2):220-224. DOI: 10.4103/1305-7456.178310. 